\title{
Adolescência em Conflito com a Lei: A Intensidade da História de Vida em Ato
}

\author{
Laura Oliveira Tomasi ${ }^{1}$ \\ Mônica Medeiros Kother Macedo \\ Pontifícia Universidade Católica do Rio Grande do Sul
}

\begin{abstract}
RESUMO - A pesquisa aborda o ato infracional a partir da história de vida de adolescentes em conflito com a lei e dos significados atribuídos por eles aos atos cometidos. Realizaram-se entrevistas semiestruturadas com quatro adolescentes com processo judicial em andamento devido a atos transgressivos. Os dados foram analisados por meio da Análise de Conteúdo e interpretados com aportes da Psicanálise. Quatro categorias finais constataram, na história de vida dos jovens, vivências extremas e recorrentes de descuido e violência no encontro com as figuras parentais. A fragilidade de recursos psíquicos dos jovens para atribuir sentido à experiência de serem confrontados com limites e a impossibilidade de experenciar e reconhecer a Lei como condição de proteção contribuem para a produção do ato transgressivo.
\end{abstract}

Palavras-chave: adolescência, lei, desamparo, psicanálise

\section{Adolescence in Conflict with the Law: The Intensity of Life History in Act}

\begin{abstract}
This study approaches infractional acts of teenagers from the perspective of their life history of conflicts with the law and the meanings assigned by them to the perpetrated acts. Semi-structured interviews were performed with four teenagers with lawsuit in process for having committed infractional acts. The data were analyzed using content analysis and interpreted with psychoanalysis contributions. In the life history of these teenagers four final categories showed evidence of extreme and recurring experiences of neglect and violence towards parental figures. The fragility of teenager's psychological resources to assign meaning to the experience of being confronted with boundaries and the impossibility to experience and recognize the law as a protective condition contribute to the production of transgressive acts.
\end{abstract}

Keywords: adolescence, law, abandonment, psychoanalysis

O termo "violência" tem amplo significado e pode abranger diferentes situações. A violência presente nos atos transgressivos ocorre a partir da intencionalidade de um ato direcionado a outra pessoa, independente do resultado produzido, o que evidencia a violação de direitos humanos e a desconsideração às diferenças e aos limites na relação com o outro. Nesse contexto, as manifestações de violência a partir de atos juvenis têm grande impacto. Para Birman (2012), o conceito de passagem ao ato corresponde a uma ação rude e brutal, que não revela qualquer indício de simbolização. É preocupante constatar o quanto adolescentes, ao se envolverem em atos infracionais, colocam em jogo as suas próprias vidas e a de outros, denunciando a precariedade de recursos emocionais para o enfrentamento de adversidades em uma etapa fundamental da vida humana (Refosco, Tomasi, Silva, Fin, \& Macedo, 2011).

Flechner (2003) destaca que os adolescentes envolvidos em atos violentos apresentam histórias de vidas marcadas por intensa violência no cenário familiar. Viñar (2004) acrescenta que o envolvimento de adolescentes em atos infracionais tem relação com o fato de terem sido privados durante a vida de um suporte imprescindível para a conquista da condição humana, ou seja, esses jovens se veem privados da "ação socializante de duas instituições básicas da modernidade: a família e a escola" (p. 1).

$\mathrm{Na}$ direção de refletir sobre os efeitos devastadores que falhas no amparo familiar e social podem produzir,

1 Endereço para correspondência: Av. Ipiranga 6681, Prédio11, Sala 926, Partenon, Porto Alegre, RS, Brasil. CEP: 9661990. E-mail: lauratomasi08@hotmail.com encontra-se em Hornstein (2008) a afirmativa de que não há psiquismo sem referência ao outro, o qual cumpre múltiplas funções: satisfaz necessidades de autoconservação, implanta sexualidade, estabelece condições de identificação e funda formas de regulação contidas na cultura. Assim, valoriza-se a ideia de um psiquismo aberto às vivências intersubjetivas, não somente no passado, mas também na atualidade, o que exige reflexões sobre as tramas relacionais e os seus efeitos na constituição da subjetividade (Hornstein, 2003). A concepção de um psiquismo aberto é reforçada por Macedo e Falcão (2005), ao referirem que essa noção pressupõe um frequente intercâmbio entre o sujeito e o objeto, dando destaque ao campo relacional e aos efeitos deste sobre os sujeitos. Serão as experiências neste campo intersubjetivo que constituirão a história de vida de um sujeito. Desta forma, cabe retomar a proposição freudiana a respeito da verdade material e a verdade histórica. Neste estudo toma-se a definição de verdade histórica considerando-se a vivência humana naquilo que transcende à crítica lógica e à realidade objetiva, mas que diz respeito interpretação dada por cada sujeito àquilo que foi experenciado (Freud, 1940[1938]/1996).

Este artigo retrata uma pesquisa realizada acerca da adolescência em conflito com a lei sob a perspectiva da história de vida de jovens que se envolveram em atos infracionais. Além disso, busca investigar os sentidos atribuídos por eles ao ato infracional cometido, na tentativa de explorar os fatores intrapsíquicos e intersubjetivos que geraram a condição de conflito com a lei. Entende-se a necessidade de buscar formas de abordar o fenômeno da 
adolescência envolvida em atos transgressivos que não a de julgamento moral. Nesse sentido, os aportes da Psicanálise se mostram como fecundo recurso de leitura, contribuindo para um olhar amplo a respeito desta problemática. Como embasamento teórico, serão priorizadas contribuições da metapsicologia freudiana. Utilizar-se-á, também, contribuições winnicottianas sobre o tema da delinquência que podem relacionar-se com a perspectiva metapsicológica da Psicanálise freudiana.

\section{Método}

\section{Participantes}

Para a participação no presente estudo, os adolescentes deveriam corresponder aos seguintes critérios: (1) ter entre 12 e 18 anos incompletos de idade; (2) estar respondendo a um processo na justiça pelo envolvimento em ato infracional; e (3) não estar em cumprimento de Medida Socioeducativa de privação de liberdade. O último critério foi assim estabelecido por sugestão dos profissionais da Instituição do Sistema Judiciário onde ocorreu a pesquisa. Esses profissionais consideraram que a oportunidade de uma narrativa da história de vida por parte de adolescentes que enfrentavam ainda uma situação de julgamento, portanto, que permaneciam em liberdade, poderia constituir-se de um importante momento de reflexão por parte desses jovens a respeito do ato infracional cometido, bem como oportunizar a problematização do sentido do ato e das consequências desta situação em suas vidas. Uma vez que o estudo buscou explorar a complexidade do ato infracional, desde a perspectiva de seu protagonista adolescente - sua história de vida-, o que se manteve pertinente diante desse critério, optou-se, então, por acatar a referida sugestão institucional visto que essa não causou interferência no objetivo da investigação.

\section{Instrumentos}

A participação dos adolescentes se deu por meio do preenchimento de uma Ficha de Dados Pessoais e Sociodemográficos e da realização de uma entrevista semiestruturada. A Ficha foi elaborada exclusivamente para esta pesquisa e buscava obter dados referentes à experiência familiar e escolar, assim como informações a respeito de atos infracionais cometidos pelos participantes e seu envolvimento com a justiça. A entrevista de questões abertas foi guiada por um roteiro no qual foram contemplados os seguintes tópicos: 1) a história de vida do adolescente; 2) o princípio da ocorrência de atos infracionais; 3) o encontro com a justiça; e 4) o significados atribuídos pelo adolescente ao seu ato infracional. A realização desta entrevista alinhou-se ao objetivo do estudo no sentido de buscar conhecer a verdade histórica (Freud, 1937/1996) ou ainda, como refere Hornstein (2013), conhecer os fatos da história seguidos da singular interpretação dada pelo sujeito a respeito do experenciado. As entrevistas, com duração de aproximadamente uma hora, foram gravadas em áudio após a devida autorização do participante e, posteriormente, transcritas.

\section{Procedimentos e Cuidados Éticos}

Esta pesquisa teve sua aprovação pelo Comitê de Ética em Pesquisa da Universidade a qual estava vinculada e o estudo iniciou a partir de então. Visando à autorização necessária para a realização do estudo foi contatada a equipe da instituição do sistema judiciário na qual ocorrem os processos pelos quais os adolescentes respondem devido ao envolvimento em atos infracionais. Após a audiência, os adolescentes que preenchiam os critérios exigidos na pesquisa eram indicados como possíveis participantes pela equipe do local. Junto ao(s) seu(s) responsável(veis), ambos deveriam explicitar a aceitação em participar do estudo por meio da assinatura do Termo de Consentimento Livre e Esclarecido. No cuidado de uma postura ética, garantiu-se ao adolescente a liberdade em aceitar ou não tornar-se um participante antes da realização da entrevista, expondo-se informações sobre o tema e o tempo que o entrevistado deveria dispor. Cabe ressaltar que foi ofertada a cada participante deste estudo a possibilidade de atendimento psicológico em uma clínicaescola da Universidade a qual se vinculou o estudo.

Inicialmente, após a concordância em participar, o entrevistador preenchia junto ao adolescente e ao seu(s) responsável(eis) a Ficha de Dados Pessoais e Sociodemográficos. O intuito de incluir o responsável nessa etapa foi o de obter informações relevantes da vida do adolescente que poderiam complementar o entendimento da história de vida contada pelo participante na entrevista. Em um segundo momento, foi realizada a entrevista individual com os quatro adolescentes. Optou-se por esse número de participantes pelo fato de que, neste estudo, priorizaram-se questões qualitativas, em detrimento a questões quantitativas, buscando uma compreensão do fenômeno em profundidade. Assim, a riqueza dos dados obtidos nas quatro entrevistas realizadas possibilitou uma relevante leitura do fenômeno da juventude em conflito com a lei.

\section{Análise dos dados}

A análise das entrevistas possibilitou a identificação de conteúdos que foram codificados em categorias de resposta, por meio da técnica de análise de conteúdo de Bardin (1991), na proposta de Moraes (1999). O método sugerido por Bardin é baseado em apenas três etapas, que são as seguintes: pré-análise, exploração do material e tratamento, e interpretação dos resultados. Moraes (1999) propõe uma releitura dessa técnica que auxilia na compreensão bruta dos dados, dividindo o processo de análise dos dados em cinco etapas: preparação, unitarização, categorização, descrição e interpretação. Para esta última etapa, o embasamento teórico psicanalítico foi o escolhido. 


\section{Resultados}

Foi possível identificar por meio dos dados obtidos na Ficha de Dados Pessoais e Sociodemográficos e nas entrevistas (Tabela 1) de todos os adolescentes participantes deste estudo, vivências de abandono parental por parte da mãe, do pai ou ambos, no período da infầncia, tendo a maioria deles residido em abrigos devido a essa condição. Dois jovens interromperam os estudos por falta de interesse e dois por motivo de expulsão por parte da escola. Anteriormente à interrupção da vida escolar, todos eles apresentaram sérios comprometimentos de desempenho na escola que abrangiam tanto a aprendizagem, ocasionando repetências escolares frequentes, como aspectos relacionais, acarretando em suspensões e expulsão por motivo de agressões físicas aos colegas. Todos os participantes cometeram atos infracionais, tendo eles respondido a mais de um processo na justiça responsável por adolescentes em conflito com a lei, recebendo Medidas Socioeducativas de Advertência, de Prestação de Serviço à Comunidade e de Liberdade Assistida.

O material decorrente do processo de transcrição das entrevistas permitiu a identificação de unidades de significado, as quais foram ordenadas em categorias iniciais. Depois de serem agrupadas, estas formaram as categorias intermediárias, que, por fim, resultaram em quatro categorias finais conforme ilustrado na Tabela 2 do Apêndice. Para a descrição das categorias finais foram utilizadas verbalizações dos adolescentes, com a finalidade de propiciar rigor e legitimidade às categorias.

\section{Discussão}

A primeira categoria final foi nomeada Efeitos da violência e do desamparo: a fragilidade do si mesmo. Pode-se constatar que os adolescentes apresentaram em

Tabela 1. Dados dos Participantes obtidos na Ficha de Dados Pessoais e Sociodemográficos

\begin{tabular}{|c|c|c|c|c|}
\hline Participantes & André & Fábio & Luciano & Marcelo \\
\hline Idade & 15 anos & 17 anos & 12 anos & 17 anos \\
\hline $\begin{array}{l}\text { Familiares envolvidos na situação de } \\
\text { abandono }\end{array}$ & Mãe e pai & Mãe e pai & Mãe e Pai & Mãe e Pai \\
\hline $\begin{array}{l}\text { Idade do rompimento do vínculo com } \\
\text { os pais }\end{array}$ & Aos 11 anos & Aos 7 anos & $\begin{array}{c}\text { Mãe aos } 11 \text { anos } \\
\text { e pai desde o } \\
\text { nascimento }\end{array}$ & $\begin{array}{l}\text { Mãe aos } 9 \text { anos e pai } \\
\text { desde o nascimento }\end{array}$ \\
\hline Passagem por abrigo & Sim & Sim & Sim & Não \\
\hline Situação escolar & $\begin{array}{l}\text { Interrupção dos } \\
\quad \text { estudos }\end{array}$ & $\begin{array}{l}\text { Interrupção dos } \\
\quad \text { estudos }\end{array}$ & $\begin{array}{l}\text { Interrupção dos } \\
\quad \text { estudos }\end{array}$ & $\begin{array}{l}\text { Interrupção dos } \\
\quad \text { estudos }\end{array}$ \\
\hline $\begin{array}{l}\text { Período no qual ocorreu a interrupção } \\
\text { dos estudos }\end{array}$ & Sétima série & Quinta série & Terceira série & $\begin{array}{l}\text { Primeiro ano do } \\
\text { segundo grau }\end{array}$ \\
\hline Motivo de interrupção dos estudos & Expulsão & Expulsão & $\begin{array}{l}\text { Desinteresse nos } \\
\text { estudos }\end{array}$ & $\begin{array}{l}\text { Desinteresse nos } \\
\text { estudos }\end{array}$ \\
\hline Registro de dificuldades escolares & Brigas & $\begin{array}{l}\text { Brigas e dificuldades } \\
\text { de manter-se em sala } \\
\text { de aula }\end{array}$ & $\begin{array}{l}\text { Brigas e desrespeito } \\
\text { a professores }\end{array}$ & $\begin{array}{l}\text { Brigas e falta de } \\
\text { atenção }\end{array}$ \\
\hline Repetências & Sim & Sim & Sim & Sim \\
\hline Séries em que repetiu & Primeira série & $\begin{array}{l}\text { Terceira e quarta } \\
\text { série }\end{array}$ & $\begin{array}{l}\text { Primeira e segunda } \\
\text { série }\end{array}$ & Sexta série \\
\hline Situação de suspensão na escola & Não referiu & Sim & Sim & Sim \\
\hline Motivo da situação de suspensão & -------- & Brigas com colegas & $\begin{array}{c}\text { Brigas com colegas } \\
\text { e desrespeito a } \\
\text { professor }\end{array}$ & Brigas com colegas \\
\hline Situação de expulsão na escola & Sim & Sim & Não & Não \\
\hline Motivo da situação de expulsão & Briga com colegas & $\begin{array}{l}\text { Brigas e faltas } \\
\text { recorrentes }\end{array}$ & -------- & -------- \\
\hline $\begin{array}{l}\text { Modalidade de atos infracionais } \\
\text { cometidos }\end{array}$ & $\begin{array}{l}\text { Furtos e tráfico de } \\
\text { drogas }\end{array}$ & $\begin{array}{l}\text { Furtos e brigas com } \\
\text { agressão física }\end{array}$ & $\begin{array}{l}\text { Roubo, brigas com } \\
\text { agressão física e } \\
\text { pichação }\end{array}$ & $\begin{array}{l}\text { Brigas com agressão } \\
\text { física }\end{array}$ \\
\hline $\begin{array}{l}\text { Audiências na justiça por ato } \\
\text { infracional }\end{array}$ & Três & Duas & Três & Duas \\
\hline Situação atual que levou à justiça & Tráfico de drogas & Furto & Roubo & Furto \\
\hline $\begin{array}{l}\text { Modalidade de Medidas } \\
\text { Socioeducativas aplicadas }\end{array}$ & Advertência & $\begin{array}{c}\text { Prestação de serviço } \\
\text { à comunidade e } \\
\text { liberdade assistida }\end{array}$ & $\begin{array}{l}\text { Advertência e } \\
\text { prestação de serviço } \\
\text { à comunidade }\end{array}$ & $\begin{array}{l}\text { Prestação de serviço } \\
\text { à comunidade }\end{array}$ \\
\hline
\end{tabular}


seus relatos da história de vida importantes experiências de abandono e descuido por parte das figuras parentais, sendo essas situações narradas como acontecimentos marcantes e permeadas de vivências próprias de uma condição de excesso. Fica evidente que os adolescentes vivenciaram condições de extremo desamparo no que diz respeito à figura da mãe, a qual deixou marcas de negligência e abandono.
A partir das histórias de vida dos jovens, percebe-se que a falta de cuidado de suas mães também ocorre em relação a elas próprias, explicitada no relato de constante uso de drogas, situações nas quais se fizeram presentes infecções causadas por doença sexualmente transmissível, e ocorrência de impulsividade com consequências de abandono. Essas experiências trouxeram impedimentos e severas limitações

Tabela 2. Categorização Inicial, Intermediária e Final dos dados obtidos nas entrevistas com os participantes do estudo.

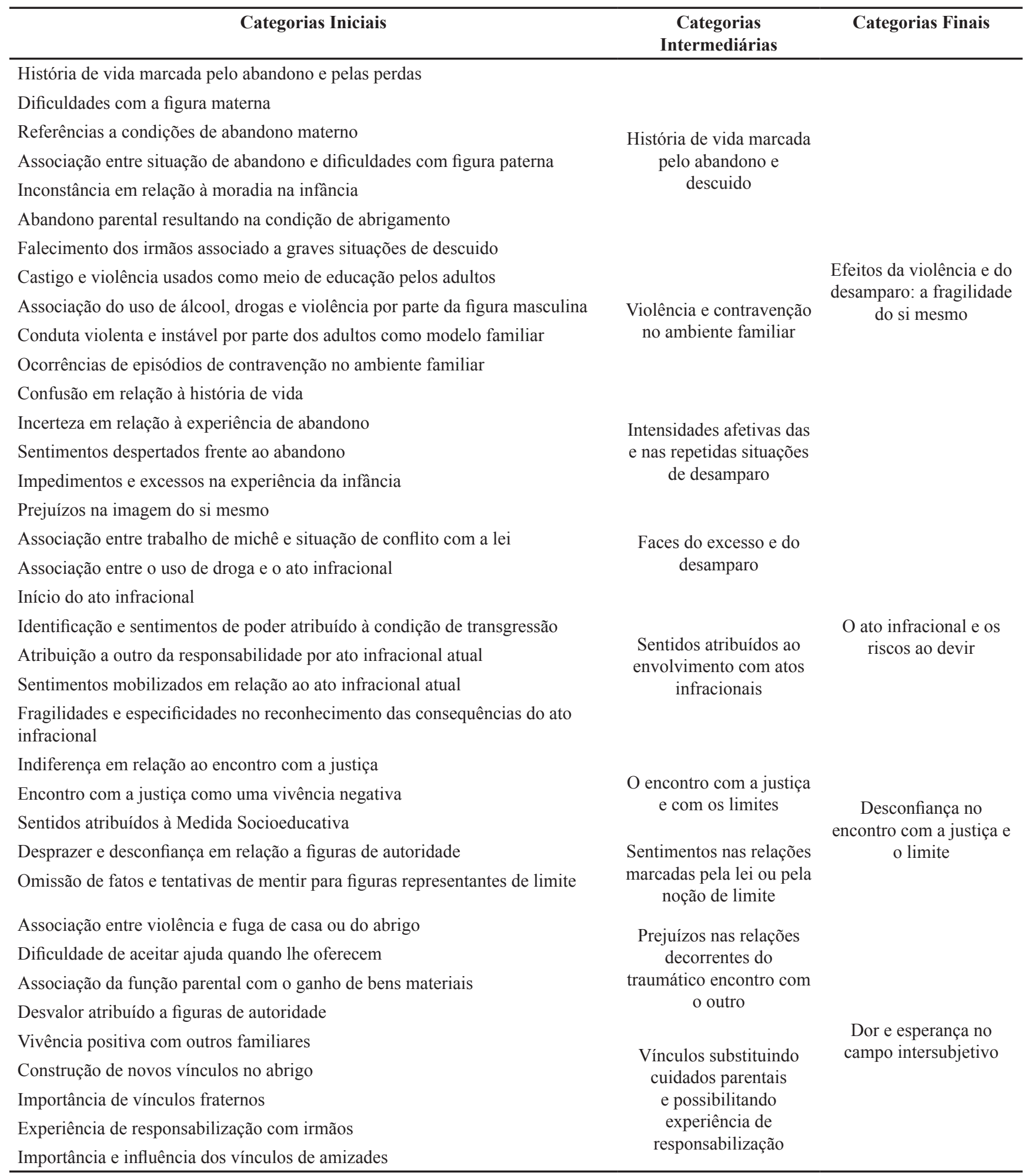


a estas mulheres no exercício do cuidado com os próprios filhos, como se pode notar na fala de André, Fábio e Marcelo:

Minha mãe que me deixava com os guris quando ela fumava pedra. Não é fácil. (André)

Minha mãe faleceu com tuberculose e HIV... Ela ficou doente. Daí ela pediu para me botar dentro do abrigo. (Fábio)

Mas daí do nada ela sumiu, sabe? Daí agora eu fiquei sabendo que ela tinha falecido...Ela quis ir embora com as amigas dela e ela foi. (Marcelo)

Notadamente as falas dos adolescentes mostram que houve um abandono real materno gerando importantes falhas no exercício de uma função essencial ao desenvolvimento psíquico de uma criança. Fica evidente, também, através das entrevistas realizadas, a condição de ausência paterna. Os quatro adolescentes foram abandonados pelos pais e, antes do abandono, relataram a ausência deste, o que trouxe sérias dificuldades em relação à figura paterna. Os comprometimentos envolvem lacunas no que diz respeito à identidade do pai, confusão de sentimentos frente à possibilidade de estabelecimento de vínculo com ele e falta de compreensão da situação de abandono. Luciano conta sobre esses conflitos:

Bem dizer eu até conheci, mas me disseram que ele não quis me assumir quando eu era pequeno. E, na verdade, ele mora na outra rua da quadra, mas eu nem falo com ele. (Luciano)

A imaturidade biológica e emocional do bebê desde os primórdios determina a necessidade inegável da presença e do cuidado do outro no que tange às necessidades básicas de um recém-nascido. Ao mesmo tempo em que o cuidador decodifica e traduz os sinais corporais do bebê, empresta palavras e afetos "que serão as inscrições fundantes da estrutura psíquica" (Hornstein, 2008, p.29). Esse encontro é o motor da vida pulsional, marcando o início da atividade de representação no recém-nascido, sendo uma vivência fundamental para a estruturação de recursos básicos que serão essenciais no enfrentamento de etapas posteriores. Dentre eles, tem-se a estruturação do ego, o qual vai se constituir a partir da ligação da energia pulsional que o outro primordial vai viabilizar; na medida em que cuida, ao mesmo tempo ele se oferece como objeto de identificação.

Para a Psicanálise, o desamparo inerente à condição humana é essencial à estruturação do aparelho psíquico ao viabilizar a instauração do desejo (Macedo, Fin, Tomasi, Refosco, \& Iensen, 2010). Entretanto, pode-se conceber o desamparo sob outra perspectiva, que o associa a um excesso o qual tem em seu âmago a condição de falha, no sentido da intensa precariedade do cuidado oferecido pelo outro, que acaba gerando drásticos efeitos psíquicos, levando, assim, a outro eixo de raciocínio. Entende-se que a descrição freudiana do efeito no campo intrapsíquico de um evento traumático pode ser associada às proposições winnicotianas decorrentes de sua leitura sobre as condições do ambiente externo. No contexto do desamparo com conotações traumáticas, o ambiente contribui significativamente, ao ficar aquém das necessidades da criança. $\mathrm{O}$ conceito de deprivação ${ }^{2}$, em Winnicott $(1956 / 2000)$, traz forte contribuição para o entendimento desta modalidade de desamparo, apontado pelo autor como sendo uma das raízes do comportamento delinquente. Conforme Winnicott (1956/2000), na deprivação, há a perda de algo bom que já foi experenciado pela criança com os cuidadores; a retirada desta experiência positiva estendeu-se por um período mais longo do que aquele em que a criança é capaz de mantê-la na lembrança. Assim, o autor afirma que, a partir da destituição de algum aspecto essencial da vida da criança, ela pode vir a manifestar comportamentos antissociais os quais podem corresponder tanto à normalidade, quanto serem indicativos do surgimento do padecimento delinquente.

Hack (2008) disserta sobre a distinção proposta por Winnicott entre privação e deprivação. Na condição de deprivação, a criança teve alguma experiência positiva com $\mathrm{o}(\mathrm{s})$ cuidador(es) que foi perdida, já na privação a criança nunca beneficiou-se dessa vivência (Hack, 2008). Salientase que, de acordo com Winnicott (1956/2000), a deprivação instaura-se no momento em que o grau de maturidade do ego permite a percepção de que a falha foi externa e não interna, e que é justamente essa percepção que acarreta o prejuízo na personalidade e a busca da cura numa nova provisão ambiental. O período de ruptura dos vínculos de André e de Luciano aconteceu aos 11 anos, de Fábio aos 7 anos e de Marcelo aos 9 anos. A ida para o abrigo, no caso de Fábio, André e Luciano, o falecimento dos pais, como ocorreu nas vidas de Fábio e Marcelo, a experiência de morar na rua que aconteceu com André denotam a deprivação nas situações extremas de abandono real por parte dos responsáveis e mostram a fragilidade da relação com as figuras parentais, na qual predominam a insegurança e a instabilidade. $\mathrm{O}$ trágico episódio da morte dos irmãos de André explicita justamente a traumática falta de cuidado e o transbordamento emocional que o acomete, resultantes de uma grave condição de descuido. Ao falar sobre o drama da perda dos irmãos, o adolescente ilustra o risco de vida a que também estava recorrentemente exposto:

Morreu os meus irmãos menores na casa queimada daquele acidente que duas criancinhas morreram queimada. Apareceu no jornal, na TV. Minha mãe foi buscar pedra pra fumar e deixou eles dentro da casa, daí nisso caiu a vela em cima da cama... A casa pegou fogo e todo mundo morreu. Não dormi, eu chorei, chorei. (André)

Ainda no terreno do desamparo, os adolescentes referiram um cenário familiar em que o descuido e a violência se faziam presentes, tanto no que diz respeito a agressões físicas e verbais por parte dos integrantes da família, quanto em relação à ocorrência de episódios de contravenção nos quais esses membros estavam envolvidos. A situação na qual a mãe se afasta para fumar crack denuncia não só a precariedade de condições desta para exercer funções de cuidadora em relação aos filhos, como também explicita a precariedade de investimentos no si mesmo. A violência por parte dos adultos mostrou-se como "recurso" de educação aplicada na infância aos participantes. A conduta violenta foi atribuída substancialmente à figura paterna, estando associada ao descontrole em função do uso de drogas e álcool, gerando temor e insegurança no convívio familiar. Dessa forma, a própria família oferece o comportamento agressivo e instável como modelo a ser seguido, o que denota carências 
de figuras de identificação qualificadas para os adolescentes nesse contexto. Fábio narra o comportamento paterno e Luciano conta a briga entre tios e irmãos contra o padrasto que agrediu a sua mãe:

Eles estavam sempre brigando. Meu pai sempre batendo na minha mãe... Usando droga. Meu pai ficava louco. Do nada ele queria agredir alguém. (Fábio)

Daí eu, meu irmão, mais o meu outro irmão e mais o meu tio peguemo ele [padrasto] e demo um pau nele. Meu irmão pegou a cara dele, o cabelo, que tem trança, e bateu, no asfalto. Acho que foi uma coisa muito certa, tinha que dar mais ainda. (Luciano)

Outro modelo negativo oferecido no ambiente familiar é o da prática da contravenção. No relato da história de vida dos jovens, é frequente o envolvimento de familiares como pai, mãe e tios em situações de roubo ou trabalhos ilegais. Muitos destes adultos estão em regime prisional. Conta André sobre sua mãe:

Uma vez ela roubou, não fosse eu, ela estaria morta. Não lembro se ela tava fumada ou bêbada. Ela pegou e queria bater num cara que tava armado, daí eu peguei e falei com o cara e deu, ela podia morrer ali mesmo. (André)

O enfrentamento de um panorama de violência e agressão na vida familiar, acrescido ao quadro de abandono real deprivação - com o qual os adolescentes tiveram que se deparar desde as origens evidenciam cenas traumáticas decorrentes da escassez de relações significativas e amorosas. A condição marcante de descuido e desamparo, que se faz presente desde muito tempo na vida dos participantes, permite constatar os danosos efeitos do excesso na precariedade e fragilidade da visão de si mesmos. Inicialmente, a imagem de si mesmo é dada à criança a partir do olhar de um outro, tendo a ver com o que ela significa para os próprios pais. Bleichmar (1985) denomina narcisação "ao processo intersubjetivo que compreende, por parte do outro significativo, uma valoração positiva do sujeito, com a concomitante expressão de prazer, e, por parte do sujeito, uma identificação com essa valoração e esse prazer" (p.92). A criança, então, se identifica com a representação qualificada que o adulto significativo tem a seu respeito, adquirindo uma identidade. No entanto, ao contrário do que se descreve como narcisação, pode acontecer, segundo o autor, que o outro significativo não esteja disponível emocionalmente para o seu bebê, comprometendo a sensação de completude necessária para a instauração do narcisismo. Nesse processo, denominado por Bleichmar (1985) de desqualificação primária, o olhar crítico e o desprazer do outro significativo, desde o início da vida da criança, resultam na identificação da mesma com essa atitude. Para o autor, os vestígios mnêmicos dessas experiências carregam-se "com algo que não é simplesmente a ausência de catexia narcisista, o que seria um vazio, e sim com a presença viva de seu oposto, da rejeição" (p. 92).

Não é de se admirar a presença de graves comprometimentos dos adolescentes em relação à noção do si mesmo, uma vez que dificilmente ocuparam um lugar significativo junto aos pais. A conduta parental de abandono e violência aponta para falhas narcísicas dos próprios cuidadores, o que reflete diretamente na maneira precária como narcisisaram os filhos. As implicações decorrentes dos parcos investimentos parentais resultam em lacunas no si mesmo e em impedimentos na nomeação de intensos sentimentos endereçados às figuras parentais.

Ah não vou falar (risos). Não posso falar, se não eu começo a chorar... (Silêncio) Às vezes eu estava no colégio,aí as mães iam buscar os filhos e só a minha mãe que não ia me buscar. Daí eu sempre dizia que ela tava trabalhando. Mas tipo, eu não sabia onde ela tava. (Marcelo)

Daí eu botei na cabeça que eu não queria mais ficar com ele. Aquele lá nunca vai ser meu pai. (Risos). Por que ele não me assumiu? (Silêncio). (Luciano)

O drástico efeito no sentimento de estima de si pode ser representado a partir da fala de André, que explicita o desvalor atribuído à maneira como se percebe, impossibilitando-o de investir em possibilidades do devir.

Não que eu seja honesto, né. Como eu te disse, agora cada um tem a sua hora de ir. Lá para cima ou para o inferno. Se eu morrer, pra nenhum eu vou ir. Não fiz o bem nem o mal, ninguém vai me querer. (André)

Pode-se estabelecer uma relação entre vivências traumáticas na infância - de desamparo, negligência e violência - e prejuízos na construção da autoestima, resultando em frágeis recursos emocionais para percorrer a complexa trajetória da adolescência. No entanto, o advento da adolescência irá demandar um intenso trabalho psíquico de significação e ressignificação de seu passado e de seu presente, disso resultando condições de investimentos no futuro. Para os adolescentes entrevistados, o ingresso nesse período é regido por fragilidades que se manifestam através do ato infracional.

Diante do exposto, estrutura-se a segunda categoria final que aborda o envolvimento dos adolescentes com atos infracionais e foi denominada $\mathrm{O}$ ato infracional e os riscos ao devir. As faces do excesso e do desamparo aparecem na conduta dos adolescentes, denotando os descuidos por si mesmo e a falta de referências no ambiente familiar e social que possam conter esse cenário de violência. André, ao associar seu trabalho como michê ao ato infracional, demonstra a falta de recursos de cuidado consigo devido à sua fragilidade psíquica para sair da situação de transgressão. Salienta-se a passividade do adolescente ao ser tomado como objeto para satisfazer a necessidade do outro. André refere sentir-se ativo na prática como michê, mas está submetido ao desejo de seu cliente, na condição de prostituição.

Estava até trabalhando de 'michê' pra não tá roubando e pra não tá traficando... O passivo é o que dá e o ativo é o que come; eu era o ativo, nunca dei pra alguém. Porque ela [cliente] quis ficar comigo e eu ia negar ficar com ela? Eu sou puto. (André)

O uso de drogas é outra dura face do desamparo. Mayer (2010), ao discorrer sobre os atos transgressivos relacionados às adições, coloca-os como resultado tanto de situações de abandonos afetivos quanto de experiências de falta de limites na infância. Essas crianças, então, "se habituam a tomar o que necessitam atuando, em lugar de pensar, falar e pedir" (Mayer, 2010, p. 51). A partir do quadro de instabilidade familiar na adolescência, da incapacidade de esperar ou de criar vias de satisfação que não impliquem condições de risco ou destrutividade, resulta uma ação impulsiva, sem ponderação a respeito das consequências do ato. A destrutividade da droga é um exemplo. Na ilusão da obtenção 
de força e potência, Marcelo, ao contar sobre os amigos, no discurso das formas de comportamento atribuídas a outro, fala de si mesmo:

Eu conheço um monte de amigo meu que tipo fuma maconha pra se aparecer pras gurias. Ah, tipo, homenzão. Sabe, assim, daí eles ficam chamando a atenção delas. (Marcelo)

Conforme Steffen (2006), os comportamentos transgressivos dos adolescentes estão relacionados a uma deficiência na organização psíquica interna, isto é, a um afluxo de energia livre e sem contenção, em que o sujeito é incapaz de metabolizá-la, dando espaço à passagem ao ato, o que evidencia um fracasso do recurso de simbolização. A ausência de registros de linguagem como recurso para processar o transbordamento pulsional encontra uma via de escoamento através da ação sem a mediação do pensamento. Os relatos do início dos atos infracionais de Fábio, Marcelo e Luciano evidenciam as modalidades de passagem ao ato que surgem concomitantes ao ingresso na adolescência e revelam os efeitos da pobreza de recursos referentes ao processo de pensamento:

Só em mercado só [fala sobre o seu envolvimento com roubo]. Pegar bolachinha. Desodorante... Eu tava com fome ia lá e pegava uma bolachinha. (Fábio)

Ah, foi discussão no futebol. Porque um me chamou de filha da puta. Daí eu não gostei. Daí eu tomei uma atitude. (Marcelo)

O bonde ${ }^{3}$, na real, começou já faz uns três anos e meio... $\mathrm{Na}$ real, a história de bonde foi uma brincadeira, começou, uns cinco, seis, se juntando... (Luciano)

Na adolescência, o ato é uma forma de descarga pulsional frequentemente utilizada pelos jovens. Os impasses e as repercussões sociais que advêm desse ato é o que diferencia os atos infracionais das modalidades de atuação típicas da adolescência. Para Savietto e Cardoso (2006), a atuação dramática é aquela na qual o adolescente é tomado por uma força pulsional que não consegue dominar, passando do impulso diretamente à ação, sem efetuar a etapa do processamento psíquico. Segundo as autoras, pode-se pensar que se trata de um ato sem sentido (sem simbolismo), no qual não existe a implicação do sujeito e, dessa forma, não há condição de responsabilização pelo seu ato. A atribuição a outro da responsabilidade pelo ato infracional mostra a ausência da percepção do que se passa consigo em relação à produção de um ato, conforme revelam as seguintes falas:

A guria que eu arrastei pro hotel traficava, eu acho... Essa daí não era a minha [a pedra de crack que acharam nos tênis dele]. (André)

É que o meu amigo já, tipo, entrou [no supermercado] e ficaram olhando e ele já começou a debochar, sabe. Daí eles pegaram, deram em nós e ficaram falando um monte de merda, lá... Não tenho culpa. (Marcelo)

O grupo de iguais para os participantes ocupa um lugar de destaque no envolvimento relativo aos atos infracionais. De acordo com Viñar (2010), as tribos cobrem e povoam o território que ficou disponível com o desinvestimento das figuras endogâmicas, e, a partir da identificação com seus pares, o jovem vai construindo sua identidade. Levando em consideração toda a instabilidade da configuração familiar e a escassez de modelos identificatórios do cenário familiar, é no bando e suas condutas transgressivas que os adolescentes encontram modelos de constituição de sua identidade, buscando um jeito próprio de ser e estar no mundo, mas atualizando o descuido. A referência de bem-estar, a sensação de poder no pertencimento ao grupo e a identificação com o modo de ser e agir de seus integrantes estão na fala de Luciano. Já Fabio associa o convívio com o grupo ao início da ocorrência de atos infracionais:

Só pedi pra entrar. Nós temos cento e dez gurizadas. Ah, eu me sinto tri bala. Acho o jeito de ser de bonde 'bala'... E todo mundo sai de galera. Bah, fecha toda a rua. Pode ver, todos os guris de bonde com boné, correntinha, com piercing. (Luciano)

Foi muito pelas influências [sobre o início do envolvimento com roubo]. (Fábio)

O envolvimento em episódios de contravenção pode corresponder a uma busca do jovem no sentido de provar, para si mesmo e para os outros, a sua masculinidade, ainda que por meio de seus atos coloque em risco a própria vida. Para Steffen (2006), no contexto de conflito com a lei, as falhas narcísicas estabelecem dificuldades de estabelecer um ideal, ou seja, frente a todo o cenário de privações, não há nesses jovens a perspectiva um futuro regido por forças de Eros. A constituição do superego acontece a partir da internalização de regras e valores sociais e é a instância psíquica encarregada de realizar a contenção interna. A formação da instância superegóica dar-se-á por meio de um processo em que estão envolvidas questões identificatórias e de constituição de um ideal de ego (Freud, 1923/1996). O superego, dessa maneira, é o sedimento não apenas da influência direta das figuras parentais, mas, também, das exigências do respectivo ambiente social.

Estudo realizado por Sena, Machado e Coelho (2006) estabelece ligações entre a juventude que comete atos infracionais e a ausência da figura paterna, como representação de limites e de valores culturalmente aceitáveis. Assim, a precariedade nos cuidados abrange a falta de qualidade nos primeiros encontros e, segundo os autores, ela se refere não só ao investimento amoroso, mas também ao que diz respeito à falha na imposição de limites. Tal constatação fica bem ilustrada pelas entrevistas realizadas neste estudo, nas quais vêm à tona relatos sobre um ambiente familiar marcado por grande instabilidade em relação ao estabelecimento de laços de afeto e por inexistência ou enfraquecimento da força da autoridade parental. Os sentidos atribuídos pelos adolescentes à contravenção fazem com que, por vezes, esta não seja percebida por eles como tal, evidenciando a fragilidade do processo de reconhecimento do limite como cuidado e da internalização de valores morais.

Por noite, os guris de bonde conseguem mais que mil conto... Cada um tem um trabalho lá. Quando nós pega uma vítima na rua, nós não dividimos entre todo mundo, vai pegar uma vítima, ali entre dois, só os dois vão ganhar né. (Luciano)

O mesmo prejuízo relativo aos recursos internos necessários à atribuição de legitimidade aos valores sociais é manifestado na percepção dos efeitos do ato infracional. Ainda que percebam e reconheçam as consequências de contravenções, há uma confusão moral na qual o ato infracional é referido como uma conduta possível e aceitável para o sujeito. 
Se fosse a terceira [refere-se à ocorrência] eu já estaria na FASE. O normal é. Ah se eu for cair, caiu né, normal. Não vai demorar muito e eu vou ta na rua. (André)

Porque não adianta assim, tipo, uma hora tu vai ser preso. Não adianta! Vá que eu

nunca fiz isso. Vá que eu vou e dá errado? (Marcelo)

Cabe uma reflexão a respeito das formas com as quais a Justiça lida com o ato infracional de adolescentes que cometem algum tipo de delito. O artigo 122, do Estatuto da Criança e do Adolescente (Brasil - Lei Federal 8.069, 1990) prevê, para os jovens que infringem a lei, a prestação das seguintes Medidas Socioeducativas: I) Advertência; II) Obrigação de Reparar o Dano; III) Prestação de Serviços Comunitários; IV) Liberdade Assistida; V) Inserção em Regime de Semiliberdade; e VI) Internação em Estabelecimento Educacional. Considera-se que, com essas medidas, o adolescente possa sentir-se responsável por seus atos, mas pondera-se ser uma situação peculiar por se tratar de uma pessoa em desenvolvimento. Levando em conta que a intenção do Poder Judiciário é promover uma experiência de responsabilização a partir da imposição de limites, surgem questionamentos acerca de como se dá o encontro do adolescente com a justiça. No campo dessa temática, apresenta-se a terceira categoria final, intitulada Desconfiança no encontro com a justiça e o limite.

Em O Mal Estar na Civilização, Freud (1930/1996) salienta que, para a constituição do processo civilizatório, a liberdade do individuo, no que se refere às expressões das pulsões agressivas e sexuais, deverá ser restringida. Nesse sentido, a justiça, como constituinte das normas civilizatórias, fica encarregada de exigir a restrição da inibição da pulsão quanto à sua finalidade, desviando sua energia para atividades em prol da coletividade (Freud 1930/1996). Logo, as leis sociais têm por objetivo normatizar as condutas dos seres humanos, favorecendo o direcionamento pulsional para atividades socialmente aceitáveis, como o trabalho, as artes, atividades intelectuais e os relacionamentos afetivos. Sabe-se que os sujeitos estão submetidos a normas sociais que foram organizadas, agrupadas e sistematizadas, passando a compor os códigos de comportamento - as Leis. A Psicanálise conta com uma gama de aportes que permitem a compreensão do processo de internalização e de inscrição da lei no aparelho psíquico. De acordo com essa teoria, é a partir da constituição de uma instância superegóica que se instalam as proibições, os tabus e os anseios internos no psiquismo (Hornstein, 2008). A formação do superego está estreitamente vinculada ao processo identificatório, isto é, a consciência moral na criança está de acordo com a de seus cuidadores ou seus substitutos (Hornstein, 2008). A lei imposta pelos cuidadores faz com que o semelhante seja reconhecido como diferente e, na medida em que a diferença impõe a constituição do limite entre o eu e o não eu, a constatação da lei passa a ter um atributo de organização e representação do significado do cuidado. As histórias de vida dos adolescentes participantes deste estudo foram marcadas pelo descuido, o qual não se restringe a aspectos narcísicos, mas também remete a fragilidade e precariedade na apresentação das noções de limites, as quais muitas vezes surgiam associadas a imposições violentas. As sérias fragilidades na instauração da lei interna podem ser notadas através da aparente indiferença dos adolescentes quanto à audiência relativa ao processo pelo qual respondem em função da acusação de envolvimento em ato infracional. A apreensão em relação à possibilidade de serem privados de liberdade parece ser o motivo de preocupação principal, não havendo desconforto em relação ao ato cometido ou suas consequências perante o outro. Em não se estabelecendo a privação da liberdade, a sensação dos adolescentes após a audiência era de alívio. Percebem-se esses aspectos nas falas de André e Luciano:

Normal como quase todas [audiências] são. Pensei que eu ia ir preso. (André)

Da audiência...eu me senti feliz que eu não fui pro abrigo. Me senti bem. (Luciano)

As entrevistas também viabilizaram conhecer a opinião dos jovens sobre as Medidas Socioeducativas que lhes são imputadas. Eles destacaram aspectos positivos das Medidas cumpridas, os quais se referem à experiência diferenciada de relações marcadas por conversa e troca, e à aprendizagem de tarefas laborais, possibilitando tanto um contato com a tecnologia (computador), quanto um envolvimento em um ambiente de responsabilidades a serem cumpridas. No entanto, como mostra Marcelo, o que prevalece é a insuficiência do tempo dessa experiência, remetendo o jovem a uma sensação de rejeição.

Fiz serviço comunitário lá no Fórum. Até gostei. Me dei tri bem com a Doutora. Ficava no computador, ficava com ela lá. Aí eu: 'bah, por mim eu fico bem mais'. Só que daí era só quatro semana. (Marcelo)

Pode-se constatar que as falhas na internalização das leis originam sentimentos de desconfiança nas relações marcadas pela noção de limites. Nas entrevistas, os relatos dos adolescentes estavam permeados de omissões e mentiras ou de tentativas de distorcer seu envolvimento com situações de atos infracionais ou de alterar informações que acarretam maior sofrimento pessoal. Estrutura-se, neste contexto, a quarta e última categoria final que foi denominada Dor e esperança no campo intersubjetivo, a qual aborda os efeitos do traumático encontro com o outro no campo intersubjetivo e as possibilidades da criação de novos vínculos no decorrer da vida dos participantes do estudo. Rother Hornstein (2006) disserta sobre os drásticos destinos no campo intersubjetivo em casos de adolescentes que vivenciaram carências ou violências no encontro com os objetos nos primórdios da constituição psíquica. Para a autora, ao mesmo tempo em que talvez desejem estabelecer novas modalidades de vínculos com os objetos, os adolescentes são acometidos pelo temor de reviverem o descuido e a violência já experenciados. André tem dificuldades em aceitar ajuda da tia que lhe oferece moradia:

A única que me ajuda é a minha tia. Ah, ela dizia pra eu ficar na casa do meu tio, quando foi vê, eu não fui lá pegar a chave, daí eu fiquei na rua. Porque eu quis também né? (André)

Os prejuízos nas relações intersubjetivas conduzem a importantes questionamentos acerca dos modelos de identificação que os jovens tomam como referência no processo de consolidação de suas identidades. Vázquez (2010) aponta que deve haver um rompimento com os objetos e vínculos infantis, abrindo espaço para o apoio em outros objetos do mundo externo com os quais o jovem possa se 
identificar. Nos relatos dos adolescentes entrevistados, podese perceber também a existência de vínculos positivos com outros familiares e cuidadores, mostrando que nem tudo é necessariamente repetição da modalidade de violência em seus vínculos. Esses vínculos matizados por outras condições emocionais são experenciados como diversos de relações nas quais o cuidado se mostrou ausente ou precário ocorrem, porém, ocorrem de forma mais eventual e assistemática. $\mathrm{O}$ valor atribuído a eles bem como o reconhecimento da insuficiência do ofertado diante da necessidade desses adolescentes, são claramente explicitados na fala de Marcelo ao contar sua experiência nos serviços comunitários e na relação que estabeleceu com a "Doutora". Ainda assim, constata-se que o relacionamento com avós, tios e tias, profissionais e monitores do abrigo mostram-se como uma possibilidade de construir e experienciar outra qualidade de encontro na vida dos jovens:

Não, sabia quem era o meu pai. Só que sempre os meus tios estavam me tratando bem... Por isso, agora, um eu chamo de pai. Faz um monte de coisas comigo. Às vezes o que ele não faz pro filho dele ele faz pra mim. (Silêncio). (Marcelo)

Foi melhorando [a vida no abrigo]. Daí depois eu conheci a monitora dona Susana, que agora é madrinha da minha irmã. E eu comecei a me relacionar com todo mundo. (Fábio)

Salienta-se a importância dos vínculos fraternos que sugerem um tipo de relacionamento diferenciado para esses jovens. Além de amenizar sentimentos de solidão advindos do abandono parental, a relação com os irmãos aparece em suas falas como oportunizando uma experiência de responsabilização e de preocupação com o bem-estar dos mesmos, revelando a importância dos investimentos fraternos. Contam Fábio e André:

De vez em quando eu converso com as minhas irmãs. Vê se elas tão bem. Como elas passaram o dia... Eu só não me senti sozinho por causa das minhas irmãs. (Fábio)

Quem levou a minha irmã fui eu [para o abrigo]. É minha obrigação eu cuidar dos menores. Porque eu me importo com eles. Eu só tenho eles por mim. (André)

O lugar que a criança veio ocupar na estrutura familiar, a forma como foi desejada e os significados que lhes são atribuídos por seus genitores/cuidadores terão relevância na subjetivação, bem como as condições sociais que marcam sua história. Viñar (2004), ao explorar a realidade social do Uruguai, também evidencia aspectos pertinentes na realidade social brasileira ao destacar que, no atual contexto histórico civilizado, "quando encontramos uma criança na rua sem família, vagando, consumindo, roubando para comer ou drogar-se, capturamos-a em nossa custódia protetora, em nossos discursos de saber para reabilitá-la" (p. 7). Nesse sentido, o autor entende que, ao invés de ter um nome, à criança é dado apenas um diagnóstico, afirmando que "devemos inventar uma lógica menos burocrática, mais elementarmente humanizante. É uma dívida com o discurso freudiano e com a juventude do terceiro milênio" (p. 7). Altoé (2010) aponta para o papel fundamental que a Psicanálise pode exercer no trabalho institucional com adolescentes envolvidos em atos infracionais, afirmando que os seus preceitos teóricos permitem uma mudança de olhar sobre eles. Conforme a autora, esse olhar considera o jovem "não mais um corpo a ser treinado, um caráter a ser emoldurado, mas uma subjetividade" (p. 63), o qual leva em conta a sua história e o ambiente onde cresceu, dando-lhe maior ou menor possibilidade de ser sujeito.

A partir do exposto, é fundamental retomar o que diz Winnicott (1956/2005) sobre a possibilidade de o ato antissocial ser um indicativo de esperança, no sentido da busca de outro quadro de referência fora do lar e da tentativa de reconstituição de algo de que o sujeito foi privado. $\mathrm{O}$ essencial nessa proposição de Winnicott é permitir que se aborde $\mathrm{o}$ ato infracional como uma forma de denúncia quanto ao desamparo experimentado, ao mesmo tempo em que ele denota a necessidade de proteção destes jovens. Constatamse, na sociedade contemporânea, sérias limitações em termos da escuta daquilo que o ato infracional demanda, uma vez que a cultura de semblantes narcisísicos exime-se de sua responsabilidade para com uma face da realidade social que foge aos ditames da performance e dos ideais.

Acredita-se que, frente ao adolescente em conflito com a lei, há uma urgência social no sentido de promover um acolhimento àquilo que demandam, isto é, o reconhecimento da dor presente no ato, o que requer uma postura respeitosa de cuidado e consideração ao sujeito que o produz. É imperioso que esses jovens tenham acesso às condições de criar palavras para nomear estas intensidades psíquicas. Dando-lhes voz, abre-se a oportunidade para novas formas de expressão nas quais o ato não precise mais ocupar um lugar único ou de primazia. Trata-se de promover um registro no qual apareça o sujeito através da palavra. Dessa forma, o cuidado oferecido ocorre no sentido de proteção, ou seja, proteger a ação, historizando-a, transformando-a através da linguagem e promovendo o acesso a recursos que deem sentido ao experimentado.

\section{Considerações Finais}

As quatro categorias resultantes da análise dos dados encontrados neste estudo tornam possível identificar, na história de vida dos jovens, vivências recorrentes de extremo descuido e violência no encontro com as figuras parentais, gerando intensa fragilidade no estabelecimento de laços de afeto com os mesmos. Verificou-se que as drásticas consequências deste quadro de desestruturação no ambiente familiar foram decorrentes da desorganização emocional e de precárias condições de exercer o cuidado por parte dos próprios cuidadores. Percebe-se que as impossibilidades dos pais/cuidadores no exercício do cuidado para/com os filhos tem relação direta com a condição de desamparo na qual aqueles também se encontram. Destaca-se, assim, a dramaticidade presente em um ciclo que reproduz violência e desamparo.

É fundamental problematizar a denominação adolescente em conflito com a lei, no sentido de pensar se ele comporta toda a complexidade que está subjacente ao ato. Afirmar que o jovem apresenta uma conflitiva em relação à lei faz alusão à instauração de uma lei que não estaria sendo respeitada. Os achados deste estudo convidam a lançar um olhar de atenção à impossibilidade da real instauração da lei no sentido protetivo e de respeito a si mesmo e ao outro que ela comporta. Quando se leva em conta a história de vida desses 
jovens, o "conflito", aqui, parece referir-se a não existência de condições intrapsíquicas que permitiriam atribuir à Lei um valor de proteção ao si mesmo e ao outro. Constatou-se que as condições psíquicas que possibilitam a um sujeito expressarse por meio de outros recursos que não atos violentos contra si ou contra o outro, o simbolismo próprio da linguagem, por exemplo, mostraram-se praticamente inexistentes ou precários nos jovens participantes desse estudo. É exatamente a fragilidade das condições de simbolização que os deixa, entre outros fatores, aprisionados nesta forma brutal e repetitiva de dar vazão à dor psíquica.

Nessa linha de raciocínio, o adolescente em conflito com a lei denuncia também o descuido da lei para com ele, ou seja, as figuras representativas da lei também não exerceram junto a ele suas funções de cuidado e proteção. Destacase, desta forma, a importância que pode ter o acolhimento institucional, como foi explicitado na fala do participante Marcelo a respeito de sua experiência no serviço comunitário. Essas experiências podem contribuir significativamente na medida em que promovem outros recursos psíquicos e inauguram modelos identificatórios que podem auxiliar na direção do estabelecimento de vínculos diferenciados com os adolescentes, os quais não visam apenas instaurar medidas institucionais punitivas. Trata-se, portanto, de importante reconhecimento da potencialidade de experiências que poderão ser, ainda mais, incrementadas e estimuladas nas instituições que acolhem esses adolescentes.

Os achados deste estudo, bem como a discussão proposta não pretendem esgotar a investigação sobre a condição da adolescência em conflito com a lei, uma vez que, ao contrário, reafirmam a complexidade desse fenômeno e a necessidade de seguir investigando a diversidade de fatores nele implicados. Sem desconsiderar aspectos próprios à singularidade das experiências destes participantes do estudo, as histórias relatadas por André, Fábio, Luciano e Marcelo desvelam as origens da dor expressa por meio de atos que irrompem e denunciam as precárias condições do si mesmo, permitindo ampliar esta compreensão a outros adolescentes na mesma condição. Oferecer a estes jovens espaços de acolhimento e de trabalho psíquico nos quais seu valor como sujeito se imponha, pressupõe não naturalizar ou ficar indiferente àquilo que seus atos de dor denunciam.

\section{Referências}

Altoé, S. (2010). A Psicanálise pode ser de algum interesse no trabalho institucional com crianças e adolescentes? In S. Altoé (Ed.), Sujeito do direito, sujeito do desejo ( $3^{\mathrm{a}}$ ed., pp. 59-68). Rio de Janeiro: Revinter.

Bardin, L. (1991). Análise de conteúdo. Lisboa: Edições 70.

Birman, J. (2012). O sujeito da contemporaneidade. Rio de Janeiro: Civilização Brasileira.

Bleichmar, H. (1985). O narcisismo: estudo sobre a enunciação e a gramática inconsciente. Porto Alegre: Ledur.

Brasil. (1990). Lei n 8.069, de 13 de julho de 1990. Estatuto da Criança e do Adolescente. Porto Alegre, CEDICA, Governo do Estado do Rio Grande do Sul.

Flechner, S. (2003). De agressividad y violencia en la adolescência. Revista Uruguaya de Psicoanálisis, 98, 163-183.
Freud, S. (1996). O ego e o id. In J. Strachey (Ed. \& Trad.), Edição Standard Brasileira das obras psicológicas completas de Sigmund Freud (Vol. 19, pp. 15-77). Rio de Janeiro: Imago. (Trabalho original publicado em 1923)

Freud, S. (1996). O mal estar na civilização. In J. Strachey (Ed. \& Trans.), Edição Standard Brasileira das obras psicológicas completas de Sigmund Freud (Vol. 21, pp. 75-171). Rio de Janeiro: Imago. (Trabalho original publicado em 1930)

Freud, S. (1996). Construções em análise. In J. Strachey (Ed. \& Trans.), Edição Standard Brasileira das obras psicológicas completas de Sigmund Freud (Vol. 23, pp. 271-287). Rio de Janeiro: Imago. (Trabalho original publicado em 1937)

Freud, S. (1996). Esboço de Psicanálise. In J. Strachey (Ed. \& Trans.), Edição Standard Brasileira das obras psicológicas completas de Sigmund Freud (Vol. 23, pp. 157-221). Rio de Janeiro: Imago. (Trabalho original publicado em 1940/1938)

Hack, S. M. (2008). Deprivação e tendência antissocial no adolescente face ao divórcio parental. (Unpublished master's dissertation). Universidade do Vale do Rio dos Sinos, São Leopoldo.

Hornstein, L. (2003). Intersubjetividad y clínica. Buenos Aires: Paidós.

Hornstein, L. (2008). As depressões: afetos e humores do viver. São Paulo: Via Lettera.

Hornstein, L. (2013). Las encrucijadas actuales del psicoanalisis: Subjetiviad y vida cotidiana. Buenos Aires: Fondo de Cultura Econômica.

Macedo, M., \& Falcão, C. (2005). A escuta da Psicanálise e a Psicanálise da escuta. Psyquê, 15, 65-76.

Macedo, M. K., Fin, J. N., Tomasi, L. O., Refosco, L., \& Iensen, S. L. (2010). Delinquência e adolescência: reflexões psicanalíticas. In M. K. Macedo (Ed.), Adolescência e psicanálise: Interseções possíveis (pp. 187-202). Porto Alegre: Edipucrs.

Mayer, H. (2010). Drogas: hijos en peligro. Buenos Aires: El Ateneo.

Moraes, R. (1999). Análise de conteúdo. Educação, 37(22), 7-32.

Refosco, L., Tomasi, L., Silva, C., Fin, J., \& Macedo, M. (2011). Adolescência e lei: Conflitivas singulares. In M. Macedo, \& B. Werlang (Eds.), Psicanálise e universidade (pp. 384-399). Porto Alegre: Edipucrs.

Rother Hornstein, M. C. (2006). Identidades borrozas. In M. C. Rother Hornstein (Ed.), Adolescencias: trayectorias turbulentas (pp. 231-248). Buenos Aires: Paidós.

Savietto, B. B., \& Cardoso, M. R. (2006). Adolescência: ato e atualidade. Revista Mal-estar e Subjetividade, 6, 15-43.

Sena, I. J., Machado, T. R., \& Coelho, M. T. (2006). A delinquência juvenil e suas relações com a função paterna. Seminário estudantil de produção acadêmica, UNIFACS, 10,1. Retrieved from http://revistas.unifacs.br/ index.php/sepa/article/ viewArticle/48.

Steffen, M. (2006). Delinquência: Privação, trauma e passagem ao ato. Pulsional Revista de Psicanálise, 188, 82-86.

Vázquez, S. G. (2010). Adolescencia, violencia y subjetivación. In S. Flechner (Ed.), Psicoanálisis y adolescencia: dos temporalidades que se interpelan (pp. 85- 94). Buenos Aires: Psicolibros ediciones.

Viñar, M. (2004). Los niños fuera de la ley. Adolescencia desamparada e infractora en la frontera de lo psíquico y lo social. (Manuscrito não publicado). 
Viñar, M. (2010). Del mundo interno y las relaciones objetales a la prioridad del outro. In S. Flechner (Ed.), Psicoanálisis y adolescencia: Dos temporalidades que se interpelan (pp. 6383). Buenos Aires: Psicolibros ediciones.

Winnicott, D. (2000). A tendência anti-social. In D. Winnicott (Ed.), Da pediatria à Psicanálise: obras escolhidas (pp. 406-416). Rio de Janeiro: Imago. (Trabalho original publicado em 1956) Winnicott, D. (2005). A tendência anti-social. In D. Winnicott (Ed.), Privação e delinquência (4 ed., pp. 135-148). São Paulo: Martins Fontes. (Trabalho original publicado em 1956)

Recebido em 10.01.2013

Primeira decisão editorial em 16.09.2013

Versão final em 16.12.2013

Aceito em 16.12.2013 